\title{
Sediment pulses and extreme events: Assessing the effect of storm characteristics on propagation dynamics
}

\author{
Celso Castro-Bolinaga ${ }^{1,{ }^{*}}$, Panayiotis Diplas ${ }^{2}$, and Robert Bodnar $^{3}$ \\ ${ }^{1}$ Biological and Agricultural Engineering, North Carolina State University, Raleigh, NC, USA, 27695 \\ ${ }^{2}$ Civil and Environmental Engineering, Lehigh University, Bethlehem, PA, USA, 18015 \\ ${ }^{3}$ Geosciences, Virginia Tech, Blacksburg, VA, USA, 24061
}

\begin{abstract}
The objective of this research is to assess the effect that extreme hydrologic events have on the propagation of sediment pulses in river corridors. These sediment-flow hazards are associated with large amounts of loose material suddenly deposited in rivers by the action of external factors or processes of natural or anthropogenic origin, including landslides, debris flows from tributaries, dam removal projects, and mining-related activities. Their occurrence is associated with severe channel aggradation and degradation, floodplain deposition, damage of infrastructure, and impairment of riparian and aquatic ecosystems. Given that the intensity of rainfall events have been significantly enhanced due to the influence of various human activities, sediment pulses are expected to become more common, with a more pronounced downstream impact as such climatic changes directly affect the magnitude, duration, and frequency of flows in riverine environments. Herein, numerical simulations were performed to characterize the propagation of a fine-grained sediment pulse for the 10-, $100-$, and 500-yr storms. Results indicate that magnitude, frequency, and duration of the storms primarily influence the temporal variation of the total sediment discharge. In particular, these storm characteristics have a marked impact on the relationship between pre- and post-pulse conditions in the river channel, the dissipation of the pulse peak discharge, and the travel time of the pulse apex.
\end{abstract}

\section{Introduction}

Recent natural and anthropogenic events highlight the geomorphic and environmental impacts associated with large amounts of loose sediment suddenly deposited in river corridors. Relevant examples include the landslide that occurred near Oso, Washington, USA in March of 2014 that deposited an estimated 8 million cubic meters of sediment into the North Fork Stillaguamish River [1], the tailings dam failure in Brazil in November of 2015 that released nearly 30 million cubic meters of mine waste into the Doce River [2], and the removal of Condit Dam on the White Salmon River in Washington, USA in October of 2011 that freed approximately 1.6 million cubic meters of impounded material [3]. All of these

\footnotetext{
* Corresponding author: cfcastro@ncsu.edu
} 
events, hereafter referred to as sediment pulses, were associated with a considerable increase in sediment load delivered to downstream reaches, and therefore, caused substantial channel and floodplain deposition, damage of infrastructure, impairment of aquatic ecosystems and drinking water supplies, and in some cases, the loss of several lives.

Sediment pulses are expected to become more common as the intensity of rainfall events has been enhanced due to the influence of various human activities [4-5]. These climatic changes will have a direct effect on the magnitude, duration, and frequency of flows in riverine environments [6]. There is a need, therefore, to develop a better understanding on the behavior of sediment pulses under severe hydrologic and hydraulic conditions that might trigger their occurrence and accelerate their propagation in river corridors. These conditions govern the reconfiguration of the deposited material, dictating sediment transport rates, concentration of suspended solids, and aggradation/degradation patterns, as well as regulate the overall time period over which geo-environmental impacts persist. This research aims to shed light on this issue by examining the fate of a fine-grained sediment pulse under the influence of the 10-, 100-, and 500-yr storms. Specifically, the objectives of this research are: (1) to examine the effect of the magnitude, duration, and frequency of storms on the propagation of sediment pulses, and (2) to quantify the impact of these disturbances on riverine environments subjected to severe hydraulic conditions.

\section{Study area}

This research focuses on a hypothetical breach of a (non-existing) tailings containment cell at the undeveloped Coles Hill uranium deposit and the subsequent propagation of the dambreak induced sediment pulse in the downstream river network. The deposit consists of an estimated resource of $54.4 \times 10^{6} \mathrm{~kg}$ of uranium [7], and it is located in the southern part of the state of Virginia, USA in a primarily agricultural region with only a few sparsely populated areas in its surroundings (Fig. 1). Due to the environmental impact that its development might have in the future, a large, comprehensive, and continuing investigation is being conducted to characterize the geological, geochemical, and hydrological conditions associated with this deposit [8-14].

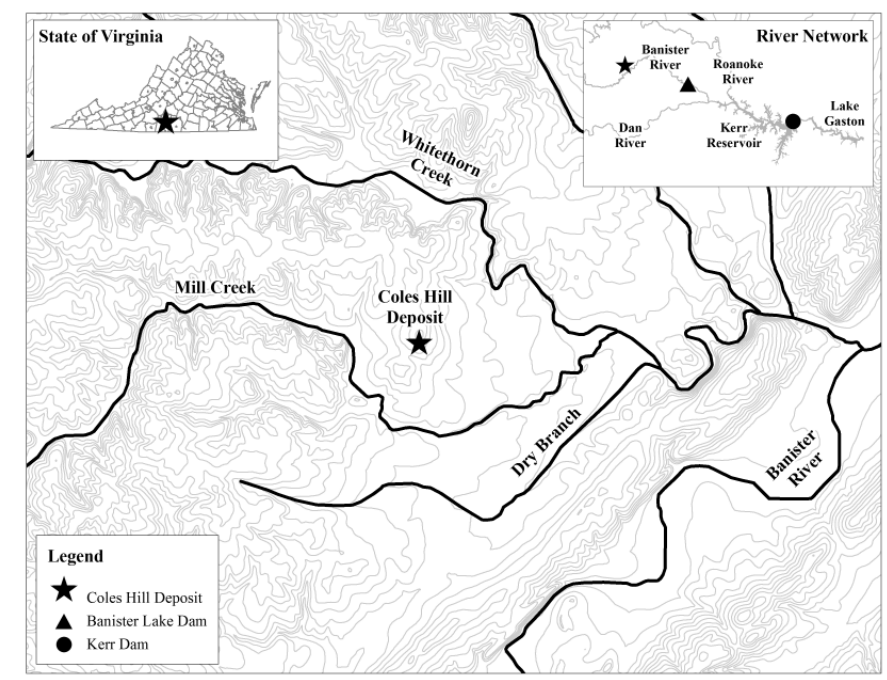

Fig. 1. Location of the undeveloped Coles Hill uranium deposit in relation to its downstream river network (contour lines are shown every $5 \mathrm{~m}$ ) (data from [15-16]). 
As depicted in Fig. 1, the deposit is surrounded by the channels of two small streams, Whitethorn Creek to the north, and one of its tributaries, Mill Creek, to the south. Whitethorn Creek flows for approximately $5 \mathrm{~km}$ from its confluence with Mill Creek to its confluence with the Banister River, which further downstream flows into the Dan River, the Roanoke River, and ultimately into major regional water bodies such as Kerr Reservoir and Lake Gaston, close to the border between the states of Virginia and North Carolina. This study focuses on the reaches of Mill Creek and Whitethorn Creek due to their proximity to the deposit, while a subsequent investigation will center on a $52-\mathrm{km}$ reach of the Banister River from its confluence with the Whitethorn Creek to the Banister Lake Dam (Fig. 1). CastroBolinaga and Diplas [10] found that the long, narrow lake that has formed upstream of this structure (i.e., the Banister Lake) hinders the capacity of the Banister River to move sediment, causing a sizable reduction of the flow velocity and boundary shear stress as water enters the reservoir. Hence, it is expected that the Banister Lake will have an important role in the fate of tailings downstream of the deposit.

\section{Modeling methodology}

The one-dimensional (1-D) morphodynamic model developed by Castro-Bolinaga et al. [17] was used to simulate the propagation of a fine-grained sediment pulse with a median grain size $\left(D_{50}\right)$ of $0.074 \mathrm{~mm}$. The model is formulated based on the St. Venant shallow water equations for the water-sediment mixture, and considers non-uniform sediment transport both as bedload and suspended load. A novel technique that applies either the decoupled or the coupled approach depending on local flow and sediment transport conditions is used to solve the system of governing equations. This solution technique has the advantage that it adopts the more suitable of these approaches within different regions of the computational domain without compromising the global accuracy and efficiency of the model. The reader is referred to the original publication [17] for detailed information regarding the formulation of the system governing equations and its associated solution methodology, as well as the employed empirical closure relations and numerical methods.

The study river network consists of two reaches: (1) $5.2 \mathrm{~km}$ of Mill Creek from a section close to the deposit to its confluence with Whitethorn Creek, and (2) $4.8 \mathrm{~km}$ of Whitethorn Creek from its confluence with Mill Creek to its confluence with the Banister River (Fig. 1). Data for constructing the river terrain model were obtained from the hydraulic model developed by Castro-Bolinaga and Diplas [10]. These data primarily include channel bathymetry and slope, and Manning's $n$ values to describe the boundary roughness. Additionally, the properties of the river bed material were determined based on sediment samples collected at various locations along the channel of the modeled reaches. Sieve analyses were performed to define their grain size distribution, and hence, the available fraction of each sediment class required to simulate non-uniform transport conditions. A summary of the main characteristics of the study river network is presented Table 1.

Table 1. Summary of the main characteristics of the study river network.

\begin{tabular}{|c|c|c|c|c|c|}
\hline Reach & $\begin{array}{c}\text { Length } \\
(\mathbf{k m})\end{array}$ & $\begin{array}{c}\text { Slope } \\
(\mathbf{m} / \mathbf{k m})\end{array}$ & $\begin{array}{c}\text { Width } \\
\mathbf{( m )}\end{array}$ & $\begin{array}{c}\text { Depth } \\
\mathbf{( m )}\end{array}$ & $\begin{array}{c}\mathbf{D}_{\mathbf{5 0}} \\
\mathbf{( m m})\end{array}$ \\
\hline Mill Creek & 5.2 & 3.6 & 7.8 & 1.7 & 2.4 \\
\hline Whitethorn Creek & 4.8 & 2.4 & 17.7 & 2.8 & 2.4 \\
\hline
\end{tabular}


The propagation of the sediment pulse was examined for the $10-\mathrm{yr}, 100-\mathrm{yr}$, and $500-\mathrm{yr}$ storms. The corresponding hydrographs, with peak discharges at the inlet of each reach provided in Table 2, were obtained from an event-based hydrologic model developed by Kingston et al. [9]. These hydrographs were implemented as the upstream boundary condition for the unsteady flow simulations, whereas rating curves of water surface elevation versus discharge generated by the aforementioned hydraulic model [10] were set as the downstream boundary condition. The number of cross-sections was defined based on the geomorphic characteristics of the river channels, resulting in an average distance between consecutive cross-sections of $158.3 \mathrm{~m}$ for Mill Creek and $150.9 \mathrm{~m}$ for Whitethorn Creek. Regarding the temporal discretization parameter, the explicit time-marching algorithm applied by the adaptive morphodynamic model of Castro-Bolinaga et al. [17] requires the maximum value of the time step $(\Delta t)$ to satisfy the Courant-Friedrichs-Lewy (CFL) stability condition. A value of $\Delta t$ of $0.1 \mathrm{~s}$ was used as a result of numerical tests carried out during execution of the model to guarantee that a stable solution was achieved.

Table 2. Peak discharge at the inlet of the modeled reaches.

\begin{tabular}{|c|c|c|c|}
\hline Reach & $\begin{array}{c}\mathbf{1 0 - y r} \\
\left(\mathbf{m}^{3} / \mathbf{s}\right)\end{array}$ & $\begin{array}{c}\mathbf{1 0 0 - \mathbf { y r }} \\
\left(\mathbf{m}^{3} / \mathbf{s}\right)\end{array}$ & $\begin{array}{c}\mathbf{5 0 0 - y r} \\
\left(\mathbf{m}^{3} / \mathbf{s}\right)\end{array}$ \\
\hline Mill Creek & 22.0 & 65.6 & 109.8 \\
\hline Whitethorn Creek & 52.4 & 155.8 & 261.9 \\
\hline
\end{tabular}

\section{Results and discussion}

The temporal variation of the discharge of total sediment load $\left(Q_{t}\right)$ at the outlet of Mill Creek and Whitethorn Creek during the sediment pulse propagation is illustrated in Fig. 2. Therein, the sediment pulse is also shown to facilitate the assessment of the pre- and post-pulse prevailing conditions for the modeled hydrologic events.

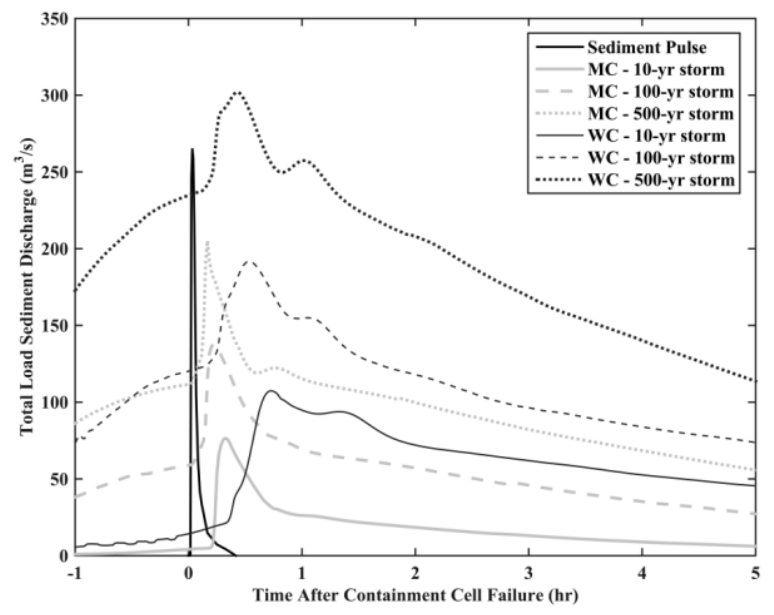

Fig. 2. Temporal variation of the volumetric discharge of total sediment load at the outlet of Mill Creek (MC) and Whitethorn Creek (WC) during the sediment pulse propagation.

Results indicate that $Q_{t}$ increases with respect to pre-pulse values as the sediment pulse migrates downstream. Fig. 2 shows that the extent of this increase is correlated with the intensity of the hydrologic event, with a less pronounced rise of $Q_{t}$ as the scale of the storm 
becomes larger. In the case of Mill Creek, the maximum increase is recorded during the 10yr storm, in which the ratio of $Q_{t}$ post-pulse to $Q_{t}$ pre-pulse (i.e., $Q_{t \text {-increase }}$ ) is 18.6 , while a minimum a value of $Q_{t \text {-increase }}$ equal to 1.8 is computed for the 500 -yr storm. Likewise, the maximum and minimum values of $Q_{t \text {-increase }}$ in the case of Whitethorn Creek are 7.4 and 1.3 for the 10-yr and 500-yr storms, respectively. This behavior is directly related to the hydraulic regime that governs the pre-pulse riverine environment. As the severity of the storm strengthens, flow velocities and boundary shear stresses within the channel increase, enhancing thus the capacity of the river to entrain and transport sediment downstream. Therefore, larger values of $Q_{t}$ are present in the reach before considering the contribution of the sediment pulse.

The peak values of $Q_{t}$ (i.e., $Q_{t-p e a k}$ ) computed in the study reaches after the failure of the containment cell are reported in Table 3. The variation of $Q_{t \text {-peak }}$ suggests that the initial sediment pulse peak discharge of $265.4 \mathrm{~m}^{3} / \mathrm{s}$ (Fig. 2) is considerably dissipated while traveling through Mill Creek, with a maximum reduction of approximately $71 \%$ for the 10 yr storm and a minimum reduction of nearly $23 \%$ for the $500-y r$ storm. Such dissipation is due to the limited capacity of the relatively small Mill Creek to accommodate the surplus of sediment. As the magnitude of the storm increases, however, this capacity increases as well and the stream is able to transport a larger amount of the deposited material downstream. Moreover, results indicate that a transient fining of the riverbed is triggered during the dissipation of $Q_{t-p e a k}$. The reduced sediment transport capacity generates a temporal accumulation of fine-grained sediment on the surface layer of the riverbed, causing the reachaveraged $D_{50}$ to be significantly reduced from its original value of $2.4 \mathrm{~mm}$ to nearly $1.0 \mathrm{~mm}$ for the 10-yr storm. Consistent with the enhanced sediment transport capacity, the transient fining process is less pronounced for the 500-yr storm (from $2.4 \mathrm{~mm}$ to approximately 1.2 $\mathrm{mm}$ ), and becomes gradually more noticeable as the storm return period increases.

Table 3. Peak discharge of total sediment load $\left(Q_{t}\right)$ in the study reaches during the sediment pulse propagation.

\begin{tabular}{|c|c|c|c|}
\hline Reach & $\begin{array}{c}\mathbf{1 0 - y r} \\
\left(\mathbf{m}^{3} / \mathbf{s}\right)\end{array}$ & $\begin{array}{c}\mathbf{1 0 0}-\mathbf{y r} \\
\left(\mathbf{m}^{3} / \mathbf{s}\right)\end{array}$ & $\begin{array}{c}\mathbf{5 0 0}-\mathbf{y r} \\
\left(\mathbf{m}^{3} / \mathbf{s}\right)\end{array}$ \\
\hline Mill Creek & 76.4 & 137.5 & 205.2 \\
\hline Whitethorn Creek & 107.4 & 191.8 & 301.9 \\
\hline
\end{tabular}

Results presented in Table 3 indicate that $Q_{t-p e a k}$ increases as the tailings sediment pulse migrates downstream. This behavior is produced by the contribution of the upland watershed of Whitethorn Creek, which adds a considerable volume of water and facilitates the transport of the material. Furthermore, the pulse migration exhibits an important translational component, as evidenced in Fig. 2 by the horizontal displacement of $Q_{t-p e a k}$. The travel time of the pulse apex between the location of the containment cell and the outlet of Mill Creek, as well as between the outlet of the latter stream and that of Whitethorn Creek are provided in Table 4. Results indicate that the time required to propagate through the study reaches is dictated by the magnitude of the hydrologic event, with larger storms enhancing the overall downstream movement of the pulse apex. The very rapid translational migration shown in Fig. 2 and Table 3, in which the pulse apex is able to travel nearly $10 \mathrm{~km}$ in less than one hour, is due to its fine-grained composition, and short-term suspended-load driven regimes that have the capacity to transport large amounts of material. 
Table 4. Travel time of the sediment pulse apex.

\begin{tabular}{|c|c|c|}
\hline Storm & $\begin{array}{c}\text { Mill Creek } \\
(\text { min) }\end{array}$ & $\begin{array}{c}\text { Whitethorn Creek } \\
\text { (min) }\end{array}$ \\
\hline $10-\mathrm{yr}$ & 19 & 25 \\
\hline $100-\mathrm{yr}$ & 13 & 19 \\
\hline $500-\mathrm{yr}$ & 10 & 16 \\
\hline
\end{tabular}

\section{Conclusions}

The sediment pulse propagation component model indicates that the magnitude, frequency, and duration of hydrologic events primarily influence the temporal variation of the discharge of total sediment load. Specifically, such characteristics have a marked impact on the relationship between pre- and post-pulse conditions, the dissipation of the pulse peak discharge, and the travel time of the pulse apex. Results suggest that the impact of the sediment pulse is more pronounced for relatively small events (e.g., 10-yr storm), as the amount of material deposited in the stream is considerably larger than that corresponding to pre-pulse conditions. On the other hand, large events (e.g., 500-yr storm) are capable of significantly enhancing the capacity of the watercourse to entrain and move sediment downstream, resulting therefore in larger transport rates before considering the contribution of the pulse.

Regarding the peak discharge dissipation and travel time of the pulse apex, the scale of the hydrologic event is directly related to the degree of attenuation and the downstream propagation velocity. Small events trigger a greater dissipation of the pulse peak discharge and a slower movement of the pulse apex, whereas the high flow rates associated with large events are able to move the pulse more rapidly, producing hence a smaller degree of attenuation of its peak discharge. A transient fining of the riverbed and an increase in the concentration of suspended solids in the water column accompany these phenomena as the stream adjusts to accommodate the surplus of material. Furthermore, the complexity of riverine environments subjected to severe hydraulic conditions is reflected by the distribution of aggradation and degradation patterns, as well as by the streamwise variation of the suspended sediment concentrations. Results indicate that backwater effects produced by large storms generate high water depths and low flow velocities that facilitate the settling of relatively coarse to medium grain sizes, while maintaining the very fine sediment in suspension for long periods of time.

\section{References}

1. Iverson, R.M., George, D.L., Allstadt, K., Reid, M.E., Collins, B.D., Vallance, J.W., Schilling, S.P., Godt, J.W., Cannon, C.M., Magirl, C.S., Baum, R.L., Coe, J.A., Schulz, W.H., Bower, J.B., 2015. Landslide mobility and hazards: Implications of the 2014 Oso disaster. Earth Planet. Sci. Lett. 412, 197-208.

2. Agurto-Detzel, H., Bianchi, M., Assumpcao, M., Schimmel, M., Collaco, B., Ciardelli, C., Barbosa, J.R., Calhau, J., 2016. The tailings dam failure of 5 November 2015 in SE Brazil and its preceding seismic sequence. Geophys. Res. Lett. 43.

3. Wilcox, A.C., O’Connor, J.E., Major, J.J., 2014. Rapid reservoir erosion, hyperconcentrated flow, and downstream deposition triggered by breaching of $38 \mathrm{~m}$ tall Condit Dam, White Salmon River, Washington. J. Geophys. Res. Earth Surf. 119. 
4. Kirschbaum, D., Adler, R., Adler, D., Peters-Lidard, C., Huffman, G., 2012. Global Distribution of Extreme Precipitations and High-Impact Landslides in 2010 Relative to Previous Years. J. Hydrometeorol. 13, 1536-1551.

5. Allan, R.P., Soden, B.J., 2008. Atmospheric Warming and the Amplification of Extreme Events. Science 321, 1481-1484.

6. Viers, J.H., 2011. Hydropower Relicensing and Climate Change. J. Am. Water Resour. Assoc. 47(4), 655-661.

7. Santoy Resources LTD, 2009. Technical Report on the Coles Hill Uranium Property Pittsylvania County, Virginia, United States of America, NI 43-101. Santoy Resources, British Columbia, Canada.

8. Gannon, J.P., Burbey, T.J., Bodnar, R.J., Aylor, J., 2012. Geophysical and geochemical characterization of the groundwater system and the role of the Chatham Fault in groundwater movement at the Coles Hill uranium deposit, Virginia, USA. Hydrogeology Journal 20, 45-60.

9. Kingston, W.J., Castro-Bolinaga, C.F., Zavaleta, E., Diplas, P., 2012. Probable maximum flood inundation modeling: a case study in southern Virginia, in: Murillo, R. (Ed.), Proc. River Flow 2012, San Jose, Costa Rica, September 5-7, 2002.

10. Castro-Bolinaga, C.F., Diplas, P., 2014. Hydraulic Modeling of Extreme Hydrologic Events: Case Study in Southern Virginia. J. Hydraul. Eng. 05014007.

11. Castro-Bolinaga, C.F., Zavaleta, E., Diplas, P., 2014. A coupled modeling effort to study the fate of contaminated sediments downstream of the Coles Hill deposit, Virginia, USA, in: Proc. Sediment Dynamics from the Summit to the Sea, IAHS Publication 367, New Orleans, Louisiana, USA, December 11-14, 2014.

12. Levitan, D. M., Schreiber, M. E., Seal, R. R., II, Bodnar, R. J., Aylor, J. G., 2014. Developing protocols for geochemical baseline studies: An example from the Coles Hill uranium deposit, Virginia, USA. Appl. Geochem. 43, 88-100.

13. Levitan, D.M., Zipper, C.E., Donovan, P., Schreiber, M.E., Seal, R.R., II, Engle, M.A., Chermak, J.A., Bodnar, R.J., Johnson, D.K., Aylor, J.G., Jr., 2015. Statistical analysis of soil geochemical data to identify pathfinder elements associated with mineral deposits: an example from the Coles Hill uranium deposit, Virginia, USA. Journal of Geochemical Exploration 154, 238-251.Tappa et al., 2014

14. US Geological Survey National Hydrography Dataset (USGS NHD), 2007. Available on-line at: http://nhd.usgs.gov/ (Jun. 23, 2014).

15. Gesch, D., Oimoen, M., Greenlee, S., Nelson, C., Steuck, M., Tyler, D., 2002. The national elevation dataset. Photogramm. Eng. Remote Sens. 68(1), 5-11.

16. Gesch, D. B. (2007). The national elevation dataset. Digital elevation model technologies and applications: The DEM users' manual. American Society for Photogrammetry and Remote Sensing, Bethesda, MD, USA.

17. Castro-Bolinaga, C.F., P. Diplas, and R.J. Bodnar, 2016. Dynamic vs. quasi-steady modeling of morphodynamic processes: A physics-based selection criterion. In: River Flow 2016, IAHR, Constantinescu, G., Garcia, M., and Hanes, D. (Eds.), 1184-1192, St. Louis, MO, USA, 12-15 Jul. 2016. 